\title{
JAVALIS NO PAMPA: INVASÕES BIOLÓGICAS, ABIGEATO E TRANSFORMACÕES DA PAISAGEM NA FRONTEIRA BRASILEIRO-URUGUAIA
}

\section{Caetano Sordi* \\ Universidade de Caxias do Sul - Brasil}

\section{Bernardo Lewgoy** \\ Universidade Federal do Rio Grande do Sul - Brasil}

Resumo: Neste artigo, discutimos algumas reações sociais e simbólicas ao processo de invasão biológica conduzido por suínos ferais da espécie Sus scrofa (javalis e seus híbridos com porcos domésticos) na região de fronteira brasileiro-uruguaia desde um ponto de vista etnográfico. A partir das conexões estabelecidas pelos agentes locais entre o javali e outros entes da paisagem pampiana, como o ladrão de gado, o eucalipto australiano e a gramínea africana conhecida como capim-annoni (Eragrostis plana Nees), sugerimos que o suíno feral e sua agência são metonímicos de processos socioambientais mais amplos, ligados às transformações que a paisagem pampiana vem sofrendo nas últimas décadas. Nesse sentido, defendemos que a espécie invasora manifesta tensões mais amplas, concernentes às relações de propriedade e trabalho no meio rural, assim como se constitui como índice mais recente da lenta decadência de um modo de vida bastante específico: a pecuária extensiva sobre campos nativos, antigo pilar da ruralidade gaúcha.

Palavras-chave: invasão biológica, javali, Pampa, pecuária.

Abstract: In this article, we discuss some symbolic and social reactions to a biological invasion process carried by feral pigs of the species Sus scrofa (European wild boars and its hybrids with domestic pigs) in the Brazilian-Uruguayan border from an anthropological point of view. Based on connections established by local agents

* Contato: caetano.sordi@gmail.com

** Contato: mlewgoy.bernardo@gmail.com 
between boars and other entities of the landscape such as cattle rustlers, Australian eucalyptus and the South-African lovegrass (Eragrostis plana Nees), we suggest that feral pigs and their agencies are metonymic for broader socio-environmental tensionalities, which are in turn linked to the deep transformations the pampean landscape has undergone in the last decades. In this sense, we argue that the invasive species manifests broader tensions concerning labour relations and landownership, as well as it stands as the most recent manifestation of the slow decadence of extensive ranching on natural grasslands, formerly the very core of Southern Brazilian rurality.

Keywords: biological invasion, Pampa, ranching, wild boar.

Em 24 de maio de 2014, doze ativistas da causa animal e um punhado de curiosos se reuniam em frente à sede do Instituto Brasileiro do Meio Ambiente e dos Recursos Naturais Renováveis (Ibama) em Porto Alegre, capital do estado do Rio Grande do Sul. Vestidos de preto, os manifestantes protestavam contra uma Instrução Normativa (IN) emitida pelo órgão ambiental pouco mais de um ano antes, em 31 de janeiro de 2013, que havia liberado a captura e o abate de javalis asselvajados europeus (Sus scrofa) e seus cruzamentos com porcos domésticos, também conhecidos "javaporcos", em todo o país, por tempo indeterminado.

Convocado pelas redes sociais online, o protesto se vinculava a atos simultâneos em outras cidades do país, sob o mote "\#Ocupalbama". Nos cartazes empunhados pelos manifestantes, liam-se frases de efeito e palavras de ordem como "Ibama: não mate, solucione"; "luto"; e "quanto vale a vida de um inocente". De modo geral, os manifestantes exortavam o órgão a cumprir a Declaração Universal dos Direitos dos Animais das Nações Unidas de 1978, segundo a qual, "todos os animais têm o mesmo direito à vida".

De acordo com uma das manifestantes, bióloga de formação e ativista pelo veganismo, o protesto tinha como foco impedir o que classificara como "massacre estatal de javalis patrocinado pelo Ibama". A seu juízo, a liberação dos abates representava uma capitulação das autoridades ambientais frente às pressões do agronegócio e da indústria de armas, ambos interessados na promoção da caça ao animal. O ápice do protesto se deu quando os manifestantes, em tom solene, representaram uma espécie de velório do javali, sendo o mesmo representado por um porquinho de pelúcia disposto no centro de um 
círculo composto por velas. Logo em seguida, foi a vez de os próprios ativistas se deitarem no chão, colocando-se a si próprios na posição de cadáveres a serem velados.

Como antropólogos das relações entre humanos e animais, era difícil deixar de notar o profundo contraste entre essa situação e aquela vivida por um de nós alguns dias antes na Câmara de Vereadores de Santana do Livramento, cidade fronteiriça com o Uruguai localizada a 492 quilômetros de distância de Porto Alegre. Durante uma audiência pública organizada pelo legislativo municipal para tratar da "praga do javali", produtores de toda a região, também conhecida como Campanha gaúcha, revezavam-se no microfone para contabilizar as graves perdas produzidas pelos javalis e suas cruzas, a quem acusavam de pisotear e destruir lavouras, assorear córregos, devorar ovos da avifauna nativa, como a ema e o quero-quero, entre outras desgraças. A principal queixa contra os suínos ferais, no entanto, provinha dos ovinocultores, que atribuíam ao Sus scrofa um imoderado apetite por cordeiros recém-nascidos.

Nessa esteira, um criador da zona conhecida como Serra do Caverá, localizada na divisa entre Santana do Livramento e Rosário do Sul, relatou ter perdido 1800 cordeiros "na boca dos javalis" no curto espaço de apenas dois anos, ao passo que outro pecuarista, sediado em região mais próxima à linha fronteiriça, defendeu que o suíno feral ameaçava não somente a subsistência dos produtores locais, mas a própria sobrevivência da "cultura gaúcha" em um dos seus redutos geográficos mais emblemáticos. O presidente do sindicato rural, também criador de ovelhas, classificara a situação como "gravíssima", e cobrava providências dos órgãos ambientais e de segurança pública. À esquerda, um vereador do Partido dos Trabalhadores (PT) ressaltou que, se nada fosse feito, os javalis ainda iriam comer "todas as ovelhas de Santana do Livramento". À direita, um parlamentar do Partido Progressista (PP) asseverou que os javalis logo começariam a "entrar na cidade" e atacar vidas humanas. Em um discurso ácido, o presidente da Câmara acusou o Ibama de ser demasiado leniente com o problema, já que apenas em 2013 fora emitida a autorização definitiva para a captura e o abate da espécie invasora.

Apesar de pequenos desentendimentos verificados aqui e ali entre os diversos grupos presentes, todos pareciam convergir quanto à necessidade de controlar a proliferação dos porcos ferais o mais rápido possível, fosse por razões econômicas (supressão de reses e ameaça de bancarrota das propriedades rurais), sanitárias (dado o status zoonótico desconhecido dos javalis), 
ambientais (pelos danos causados pelos suínos ferais à fauna e à flora do bioma pampa) ou de segurança pública (dada a necessidade de se regular o uso de armas em expedições de caça). Para o representante do Clube de Tiro local, não havia outro jeito de vencer a "guerra" contra o javali se não "desburocratizando" o registro de armas junto ao Exército, o que, no longo prazo, implicaria até mesmo uma flexibilização do Estatuto do Desarmamento, promulgado em 2003.

Diversamente do que observaríamos em Porto Alegre alguns dias depois, em nenhum momento dessa audiência pública os javalis foram colocados na posição de vítimas da violência e do desejo de sangue humanos. Ao contrário, vigorava entre os presentes uma atmosfera de unanimidade quanto ao papel de algoz representado pelo suíno asselvajado, cuja presença ameaçadora se fazia sentir a partir da exibição de um troféu de caça bem no centro do plenário: nada mais, nada menos, que uma enorme cabeça empalhada de javali macho, com suas ameaçadoras presas expostas e eriçados pelos cervicais a corroborar materialmente as alegações de predação trazidas pelos ovinocultores. Nada mais distante, portanto, do pequeno porquinho de pelúcia trazido pelos militantes animalistas como representação do animal em seu velório simbólico.

Evocamos esse exemplo de duas posições contrastantes sobre um mesmo animal para ilustrar alguns tópicos que gostaríamos de discutir naquilo que se segue. Em termos científicos, o processo conduzido por javalis europeus e seus híbridos no Pampa brasileiro-uruguaio é um caso clássico do que biólogos e ecólogos chamariam de um processo de "invasão biológica", que, por sua vez, ocorre quando "indivíduos de uma espécie não nativa a uma região chegam a ela com assistência humana e estabelecem uma população duradoura" (Simberloff, 2013, p. 2, tradução nossa). Ainda de acordo com a abordagem científica mais aceita, se essa população consegue se proliferar e passa a exercer impactos negativos sobre o ambiente receptor (p. ex., tomando o nicho ecológico de espécies nativas similares, ou alterando o ciclo de nutrientes dentro de um ecossistema particular), a espécie é então classificada como "espécie exótica invasora" (doravante, EEI).

Com efeito, o Sus scrofa, em suas mais variadas linhagens e cruzamentos, é considerado um dos vertebrados com maior potencial invasor do mundo, o que se explica por grande capacidade de adaptação ambiental, sua dieta onívora e sua alta prolificidade (Barrios-García; Ballari, 2012). Bem 
por isso, o animal figura na lista das " 100 piores espécies invasoras do mundo" (Lowe et al., 2004), espécie de catálogo produzido e periodicamente atualizado pelo Invasive Species Specialist Group (ISSG), consórcio de especialistas no problema vinculado à União Internacional para a Conservação da Natureza (UICN).

A UICN identifica as EEIs como a segunda maior ameaça a biodiversidade global, perdendo apenas para a supressão antropogênica de hábitats naturais (Simberloff, 2011, 2013). Por esse motivo, a Convenção da Diversidade Biológica (CDB), assinada durante a Cúpula da Terra de 1992, no Rio de Janeiro, obriga seus países membros a "impedir que se introduzam, controlar ou erradicar espécies exóticas que ameacem os ecossistemas, hábitats ou espécies" (Brasil, 2000, p. 12).

Desde lá, instrumentos e protocolos globais, como a supracitada lista das "100 piores espécies exóticas invasoras do mundo" (Lowe et al., 2004), têm auxiliado governos e agentes locais a promoverem políticas nacionais de controle e erradicação de espécies invasoras. No caso brasileiro, o decreto 2.519 de 16 de março de 1998, que regulamenta a CDB no país, recomenda o enfrentamento dos casos de invasão biológica a partir do princípio de precaução, segundo o qual "a falta de certeza científica não deve ser usada como justificativa para prorrogar ou deixar de implementar ações de erradicação, contenção ou controle" (Oliveira; Pereira 2010, p. 175).

Em 2006, o Ministério do Meio Ambiente instituiu uma Câmara Técnica Permanente sobre EEIs, resultado de esforços interinstitucionais que vinham sendo conduzidos pelo órgão desde 2001. O principal produto dessa Câmara Técnica foi a "Estratégia Nacional para EEIs", aprovada pela resolução n. 5 de 21 de outubro de 2009 da Comissão Nacional da Biodiversidade (Conabio). Mesmo assim, Oliveira e Machado (2009, p. 378-379) identificam uma "dispersão dos instrumentos legais e normativos aplicados à matéria”, marcada "pela sobreposição espacial da atuação de várias instituições de fiscalização". Longe de ser uma particularidade brasileira, essa dispersão se repete em muitos países do mundo, dado o paradoxo envolvido na regulação de seres que ignoram as fronteiras e limites estabelecidos pela sociedade humana (Bevilaqua, 2013).

Todavia, não obstante o crescente apelo do tema nas esferas leiga e científica, a assim chamada "biologia das invasões" tem sido alvo de inúmeras críticas em tempos recentes, assim como as políticas públicas desenhadas a 
partir de seus princípios. Essas críticas partem não apenas de movimentos como os anteriormente descritos, de corte animalista e contrários à autorização da caça de animais exóticos, mas também de acadêmicos, pesquisadores e divulgadores científicos vinculados tanto às ciências sociais e humanas quanto às próprias ciências biológicas.

No campo das ciências sociais, a crítica à biologia das invasões enfatiza a relatividade de conceitos como "nativo" e "exótico". Nesse sentido, muitos autores argumentam haver uma continuidade perturbadora entre as reações sociais à EEIs, de um lado, e determinados discursos racistas e xenófobos de outro (Sagoff, 2011; Subramaniam, 2001; Tsing, 1995; Woods; Moriarty, 2001). Já nas ciências biológicas, as críticas do conceito de EEI têm defendido a necessidade uma abordagem mais "neutra" sobre o assunto (Colautti; Mc Isaac, 2004), de modo a salvaguardar sua objetividade científica. Segundo Larson (2005), esse esforço passaria pela a eliminação de metáforas militares e territoriais que, inevitavelmente, impregnam o discurso da invasão biológica, seja na literatura acadêmica, seja perante o público em geral. Outros autores, como Davis (2011) e Pearce (2015), questionam a própria dimensão do impacto negativo causado pelas introduções biológicas a nível global, contrapondo-se ao tom alarmista adotado por biólogos das invasões mais ortodoxos como Daniel Simberloff $(2011,2013)$.

Já Lidström et al. (2015) argumentam que o excessivo foco sobre a agência deletéria de algumas espécies acaba por reduzir articulações socioambientais complexas a um binarismo contraproducente e simplista, do tipo "nativo, bom / exótico, mau". Em contrapartida, esses autores defendem uma abordagem integrativa sobre o fenômeno das invasões biológicas, rastreando as condições que proporcionaram a expansão das EEIs em questão e os demais processos de alteração do meio ambiente e da paisagem a que esses fenômenos estão articulados.

Nessa linha, argumentaremos neste artigo que, mais do que metáforas para tipos humanos indesejados, as reações sociais suscitadas pelos javalis e javaporcos na fronteira brasileiro-uruguaia são, na verdade, metonímicas de tensões socioambientais que transcendem o processo de invasão biológica protagonizado pela espécie. Para isso, é preciso recordar a diferença entre metáfora e metonímia, de fundamental importância para nosso argumento: enquanto na primeira se estabelece uma homologia ou analogia entre os termos significantes, na segunda, a função significante se baseia em uma relação de 
contiguidade ou pertencimento entre os termos, que normalmente se dá entre parte e todo, mas que também pode se dar entre causa e efeito, continente e conteúdo, etc. ${ }^{1}$

De fato, o par conceitual metáfora/metonímia possui longo histórico em antropologia, tendo servido, no estruturalismo, para se discutir questões de natureza teórica como a relação entre totemismo e sacrifício, continuidade e descontinuidade, mito e ritual (Lévi-Strauss, 1989; Viveiros de Castro, 2015, p. 162-170). Aqui, por ora, evocamos o conceito de metonímia à maneira mais simplificada de Charis Thompson (2002) em "When elephants stand for competing philosophies of nature", artigo em que essa autora analisa como diferentes disputas-chave em ciência, epistemologia, governança e justiça distributiva ressoavam e se manifestavam no manejo de elefantes no Parque Nacional de Amboseli, Quênia. Para Thompson, as controvérsias observadas em campo sobre os elefantes eram metonímicas dessas disputas-chave para além dos elefantes, já que as atualizavam e as concretizavam desde uma determinada forma.

Cremos que algo similar pode ser dito sobre o javali: em sua emergência como problema ambiental no sul do Brasil, disputas-chave e tensões constituintes de diversos campos da vida social vêm à tona, assim como seu manejo como EEI manifesta diferentes modos de engajamento (Ingold, 2000) com o ambiente e os animais. Primeiramente, apresentaremos um breve recorrido da história ambiental do bioma Pampa desde o ponto de vista das diversas introduções biológicas que o consolidaram da maneira com que o conhecemos hoje. Nesse sentido, argumentaremos que o javali não adentra e produz efeitos negativos um ecossistema "nativo" prístino e intocável, mas sim em um ambiente marcado por sucessivos projetos de domesticação da paisagem e aproveitamento socioeconômico de seu potencial produtivo. Em seguida, discutiremos as analogias traçadas pelos próprios interlocutores da

\footnotetext{
Segundo o Dicionário filosófico de André Comte-Sponville (2003, p. 187) a metáfora "é uma figura de estilo. É uma comparação implícita que faz utilizar uma palavra no lugar da outra, em razão de certas analogias ou semelhanças entre os objetos comparados." Já na metonímia, "uma palavra é utilizada no lugar do outra, não em virtude de uma comparação implícita, mas em razão de uma relação, mais ou menos necessária e constante, de vizinhança ou interdependência: por exemplo, quando o efeito é designado por sua causa, ou vice-versa ('a pálida morte misturava os sombrios batalhões'), o conteúdo pelo continente ('a rua ensurdecedora em torno de mim urrava'), o todo pela parte (se a relação for puramente quantitativa, do menos ao mais ou do mais ao menos, trata-se então de uma sinédoque: 'trinta velas, no Cid, para designar trinta naus')" (Comte-Sponville, 2003, p. 389).
}

Horizontes Antropológicos, Porto Alegre, ano 23, n. 48, p. 75-98, maio/ago. 2017 
pesquisa entre o javali e outras EEIs cuja expansão ameaça a reprodução de seu modo de vida, mormente a gramínea africana conhecida como capim-annoni (Eragrostis plana Nees) e os monocultivos florestais de pínus (Pinus sp.) e eucaliptos (Eucalyptus sp.).

Por fim, examinaremos como a animalidade do javali - isto é, sua constituição como "força vívida, móvel, imprevisível e dotada de finalidade" (Lestel, 2011, p. 41) - estabelece uma diferença crucial no modo com que esse processo de invasão biológica é pensado e encarado pelos interlocutores, em contraste com a ameaça representada pelas EEIs vegetais supracitadas. Nessa esteira, procuraremos demonstrar que, além de metonímico das transformações ambientais representadas também pelo capim-annoni e pelos monocultivos florestais, o Sus scrofa é sintomático da territorialização da Campanha gaúcha como fronteira política e pastoril, dadas as analogias estabelecidas entre predação suína e furto de gado, ou abigeato.

\section{Um ambiente em constante mutação}

O Pampa é um bioma campestre, temperado e subtropical, que cobre mais de $750.000 \mathrm{~km}^{2}$ de área no sudeste da América do Sul. Suas planícies férteis e onduladas compreendem as províncias mais orientais da Argentina, a chamada "Metade Sul" do Rio Grande do Sul e a República Oriental do Uruguai - esta última, em toda sua integridade. Apesar da sua localização estratégica em torno do estuário platino, sua ocupação pelos poderes coloniais ibéricos foi mais lenta, tardia e demograficamente mais esparsa que em outras regiões. A cultura do gado se estabeleceu na região entre os séculos XVI e XVII por intermédio dos jesuítas espanhóis, cujas "vacarias" - extensos criatórios naturais de bovinos, equinos e muares - serviam de reservatório alimentar para suas reduções indígenas.

Com o colapso da experiência missioneira, por volta do século XVIII, o gado se feralizou e dispersou-se pelo território do atual Rio Grande do Sul, virando objeto de cobiça para os colonizadores de ambas as margens do Rio da Prata. Nesse período, o gado era mais caçado do que propriamente criado, no que também incidiu a aquisição de habilidades pastoris e equestres por parte das populações indígenas da região platina (Farinatti, 2007; Pesavento, 1994). O estabelecimento de uma economia de tipo pecuário propriamente dito - isto é, onde impera o acesso dividido à terra e aos animais (Ingold, 1980) - 
desenvolveu-se quase um século depois, concomitantemente às violentas guerras de definição fronteiriça travadas entre as coroas portuguesa e espanhola e suas nações sucedâneas, entre o final do século XVIII e meados do XIX.

Como colocam Baretta e Markoff (1978, p. 593, tradução nossa), essa dinâmica de apropriação pecuária do ambiente pampiano, calcada na grande propriedade e no pastoreio extensivo, engendrou um contexto social em que "a violência e a negociação política estavam no centro da vida social e econômica", e onde habilidades pastoris possuíam "imediata aplicação no domínio da guerra pré-moderna” (Baretta; Markoff, 1978, p. 604, tradução nossa). Ecologicamente, a introdução de animais de rebanho eurasianos alterou profundamente a paisagem do Pampa, de modo que Crosby (2011) o considera um exemplo paradigmático do "imperialismo ecológico" europeu.

Durante boa parte da sua história ambiental, o Pampa foi considerado pelas elites dos seus países como uma paisagem pobre, cuja imensidão e monotonia produziriam modos de sociabilidade bárbara e incivilizada. Certa literatura oitocentista argentina e uruguaia atribuía esse barbarismo da paisagem aos violentos padrões de engajamento humano-animal requeridos pela pecuária extensiva. Para esses autores, uma reforma da sociedade implicaria uma reforma espiritual não apenas dos homens e seus costumes, mas principalmente dos seus modos de habitar e apropriar a paisagem. Em seu ensaio Facundo: civilização e barbárie, publicado em 1845, o escritor - e posteriormente presidente - argentino Domingo Faustino Sarmiento (1811-1888) argumenta que os habitantes do Pampa possuiriam "uma resignação estoica frente à morte violenta" (Sarmiento, 2004, p. 60, tradução nossa), obviamente derivada das suas lidas pastoris.

Do outro lado do Rio da Prata, Barrán (2012) registra a vigência de uma batalha ideológica no Uruguai oitocentista entre uma suposta "civilização", representada pelas cidades e a costa, e uma suposta "barbárie", ou "atraso", representados pelo campo e a hinterland fronteiriça, o que reverberava as divisões políticas da elite oriental entre as facções blanca e colorada. Para Álvarez (2012), a dicotomia agricultura versus pecuária era outro avatar dessa mesma batalha, sendo a primeira relacionada com a modernidade e o progresso econômico, e a segunda, com a tradição e o atraso.

No Brasil, em contrapartida, a literatura clássica sobre o Pampa tendeu a desenvolver uma visão mais positiva e apologética dessa paisagem e seu habitante prototípico, o "gaúcho". Posteriormente, essa mesma literatura foi alvo 
de críticas da historiografia marxista, que via nela uma "ideologia da produção do trabalho" (Freitas, 1980; Gonzaga, 1980) dedicada a legitimar a exploração do proletariado rural sulino. Em Populações meridionais do Brasil (1920), por exemplo, Oliveira Viana (2005, p. 11) fornece uma imagem quase idílica das lidas campeiras, como se estas se constituíssem quase em uma recreação para o gaúcho. O corolário dessa liberalidade, argumenta Vianna, seria o estabelecimento de relações não hierárquicas, quase democráticas, entre patrões (estancieiros) e empregados (peões), o que de fato dificilmente condiz com a realidade desses vínculos (Farinatti, 2007; Pesavento, 1994).

De qualquer modo, independentemente das suas visões contrastantes sobre a planície e seus habitantes, as elites nacionais dos três países formadores do Pampa sempre procuraram aumentar a produtividade econômica do bioma, para além do baixo retorno fornecido pela pecuária extensiva em moldes tradicionais. Durante as primeiras décadas do século XX, havia uma crença comum em Buenos Aires, Montevidéu e Porto Alegre - esta última, capital de um estado então governado por uma ditadura regional de corte positivista e teoricamente "cientificista" (Pesavento, 1994) - de que um padrão mais diferenciado e produtivo de ocupação do Pampa seria possível, desde que mediado pelos mais recentes avanços da pesquisa agronômica e veterinária. Tal concepção acabou por fomentar uma nova onda de introduções biológicas, destinadas a modernizar a pradaria de acordo com suas expectativas de modernização.

Um dos representantes mais notáveis desse movimento foi o jurista, diplomata e político Joaquim Francisco de Assis Brasil (1858-1938), que transformou sua própria estância, conhecida como Granja de Pedras Altas, em estação experimental para inovações agropecuárias. Assis Brasil e seus parceiros, vários dos quais ligados às nascentes escolas de agronomia de Pelotas e Porto Alegre, foram responsáveis pela introdução de inúmeras estirpes animais e vegetais no Rio Grande do Sul, dentre as quais o eucalipto e o cavalo árabe. O melhoramento genético do gado crioulo gaúcho também foi preconizado em Pedras Altas, a partir do seu cruzamento com raças europeias.

Do outro lado da fronteira, o aristocrata de origem argentina Aarón de Anchorena (1877-1965) repetira feitos similares em sua propriedade, localizada no departamento uruguaio de Colônia. Para além dos seus experimentos agronômicos e zootécnicos, Anchorena dedicou sua estância - hoje em dia, residência de verão do presidente da República - a experimentos com jardinagem e aclimatação de plantas exóticas, incluindo, mais uma vez, o eucalipto.

Horizontes Antropológicos, Porto Alegre, ano 23, n. 48, p. 75-98, maio/ago. 2017 
Um entusiasta da arte cinegética, o aristocrata também introduziu na propriedade diversos animais de caça maior. Um desses animais era o cervo axis (Axis axis), originário do subcontinente indiano. $\mathrm{O}$ outro, o javali europeu.

Por esse motivo, Lombardi et al. (2007) consideram que os espécimes importados por Anchorena no início do século XX foram o propágulo da invasão de javalis que hoje se faz sentir nos campos de Livramento e região. Uma vez em liberdade, os animais prosperaram na República Oriental, cruzando repetidas vezes com porcos domésticos ou domésticos feralizados. Em 1982, o país declarou o Sus scrofa como praga. Em 1996, como espécie de "livre caça". Além disso, na mesma época em que Anchorena importava seus javalis, outra população da espécie se estabelecia na província argentina de La Pampa, também para propósitos cinegéticos. Tal como no Uruguai, alguns animais escaparam, cruzaram os Andes e desencadearam um processo de invasão biológica no Chile, por volta de 1958 (Skewes; Jaksic, 2015).

No Rio Grande do Sul, Debert e Scherer (2007) consideram que uma combinação entre migração espontânea e contrabando de animais acabou provocando a invasão. Cabe notar o quanto a histórica permeabilidade da fronteira brasileiro-uruguaia foi decisiva para o desencadeamento do processo, o que também remete à questão do abigeato e do contrabando como delitos prototípicos da região da fronteira. Quanto à migração espontânea dos animais, Debert e Scherer defendem que uma seca muito severa, ocorrida em 1989, baixara o nível do leito do Rio Jaguarão, facilitando a passagem de vários espécimes em um trecho de fronteira mais ao sul de Santana do Livramento.

De fato, registros da presença de porcos ferais são notavelmente mais antigos na zona de Jaguarão, Herval e Bagé que em Livramento e Rosário do Sul. Conforme os gestores da Área de Proteção Ambiental (APA) do Ibirapuitã, unidade de conservação federal que compreende boa parte da zona rural destes dois últimos municípios, os primeiros relatos de javalis no interior da unidade remontam a 2007. O crescimento exponencial dos mesmos, contudo, só se deu a partir de 2010, coincidindo com o recrudescimento das queixas de predação de ovinos. Naquele ponto, a situação evoluíra de tal forma que, já em 2011, os gestores da APA, ligados ao Instituto Chico Mendes de Conservação da Biodiversidade (ICMBio) convocaram uma primeira reunião técnica multissetorial para discutir o assunto. Representantes de órgãos ambientais uruguaios foram convidados, no que partilharam com seus equivalentes brasileiros sua tragédia mútua. 
Nessa altura dos acontecimentos, no entanto, os braços do Estado brasileiro ainda se encontravam engessados frente ao javali, pois o Ibama ainda não havia emitido a Instrução Normativa contra a qual protestavam os animalistas referidos no início deste artigo. Respeitando a lógica de que agentes públicos só podem agir a partir do que dita a lei - ao contrário do cidadão comum, que pode fazer tudo aquilo que a lei não veta -, foi somente após a promulgação da IN 03/2013 que o ICMBio pôde, finalmente, estabelecer uma estratégia conjunta de manejo dos javalis com os proprietários da APA.

\section{Ameaça vegetal, animal e a etologia da ilicitude no contexto fronteiriço}

A biologia das invasões possui diversos instrumentos para modelar o desenvolvimento temporal de invasões biológicas desde o momento em que uma espécie é introduzida em um novo ambiente até seu estabelecimento definitivo junto às demais espécies autóctones (Simberloff, 2013). Os dados coletados pelos agentes do ICMBio na APA do Ibirapuitã e arredores, ainda que reveladores do modo com que os animais penetraram e avançaram sobre território brasileiro, pouco informam além do fato de que o número de avistamentos e ataques à lavoura e à produção animal aumentou consideravelmente a partir de 2010. Como, quando e por que motivos isso aconteceu, ainda é bastante difícil de precisar. Histórias de introduções e solturas intencionais abundam na região, assim como teorias conspiratórias de diversos matizes.

Para muitos habitantes locais, no entanto, existiria uma conexão bastante forte entre a recente proliferação de javalis na região de Livramento, de um lado, e a massiva expansão de florestamento industrial no lado uruguaio da fronteira, de outro. Durante a audiência pública já referida, uma veterinária da prefeitura - que posteriormente seria nomeada secretária municipal da Agricultura - chegou a levantar a hipótese de que a expansão da monocultura florestal no Uruguai estaria por trás do crescimento do número de javalis no lado brasileiro, o que contou com o assentimento de vários dos presentes. Em outras ocasiões do trabalho de campo, a relação entre as duas espécies exóticas foi constantemente trazida à baila, o que indica a vigência de uma percepção interseccional dos problemas ambientais que afetam o Pampa. Mas de que maneira javalis e monocultivos poderiam estar relacionados?

Em anos recentes, a expansão dos monocultivos florestais de eucaliptos e pínus converteu-se em uma preocupação ambiental crescente na América 
do Sul, na esteira do deslocamento da indústria do cloro e do papel em direção ao sul global (Bacchetta, 2009). Ambientalistas da região platina acusam os monocultivos florestais de formarem verdadeiros "desertos verdes" no Pampa, homogeneizando a paisagem e comprometendo a biodiversidade campestre. Um bom exemplo das interpretações êmicas da relação entre os monocultivos florestais e a expansão do javali pode ser extraído do seguinte depoimento, coletado durante o trabalho de campo junto aos proprietários rurais da APA do Ibirapuitã. Trata-se das expectativas de futuro de um ovinocultor chamado José Luiz, o qual, em tom de grande consternação, relatou-nos ter perdido $80 \%$ da sua produção anual de cordeiros para os porcos ferais. Disse-nos ele:

Tchê, eu tenho um amigo que estudou nos Estados Unidos e ele me disse o seguinte. Talvez tu não tenha nunca ouvido isso aí. Mas o cara é uma pessoa, assim, de alta cultura, ele teve estudando na Europa, estudou nos Estados Unidos, e me disse o seguinte: os americanos têm um levantamento, que diz que, no Rio Grande do Sul, nas próximas décadas, fica só reflorestamento, leite e soja. Pecuária de corte? Isso termina. Ele já me disse isso há uns 14 anos atrás, e eu acho que nós estamos realmente indo por este caminho. A pecuária tá encolhendo cada vez mais. Tá ficando em áreas marginais, em áreas de campo mais barato, tá entrando o reflorestamento, tá entrando a soja, principalmente a soja, e o gado de leite. (Transcrição, junho de 2015).

Como esse depoimento ilustra, alguns criadores de animais da região consideram que a expansão da agricultura mecanizada e dos monocultivos florestais sobre o campo nativo revela algo sobre a decadência da sua própria atividade. Para Alexandre, outro proprietário sediado no interior da APA, o declínio da pecuária como modo de vida na Campanha se daria em contiguidade causal com o problema do javali, de modo que seria difícil separá-los historicamente:

Daqui a cem anos, toda essa reserva não vai ter mais criação de ovinos e nem de bovinos. Ela vai ser só mato, e só javali. As áreas pastoris tão diminuindo a cada dez anos cerca de $10 \% \ldots$ então, eu te diria o seguinte: o meu neto não vai sobreviver de lá [propriedade da família]. Pode ser que a minha filha sobreviva. Mas meu neto, só de árvores, não vai sobrevive. (Transcrição, junho de 2015).

Outro produtor, chamado La Hire, classificou o problema dos javalis como uma verdadeira "tragédia", visto que o animal estaria "pressionando muita gente 
a parar de criar ovelha", sobretudo os pequenos proprietários. Como consequência disso, o campo nativo estaria correndo o risco de ser abandonado, abrindo espaço para que, no futuro, "tudo isso aqui se transforme em florestamento".

É importante destacar que essa percepção de fatores adversos operando conjuntamente contra a permanência da pecuária tradicional transcende o grupo dos ovinocultores, abrangendo também agentes políticos, científicos e estatais locais. Em uma reunião técnica organizada pelos gestores do ICMBio no Sindicato Rural de Rosário do Sul, em maio de 2015, um biólogo da Secretaria Municipal de Meio Ambiente de Santana do Livramento fez a seguinte observação:

Muita gente não se dá conta que não é apenas um simples cordeiro que tá sendo prejudicado... é toda uma rede laneira, que a gente tem forte em Santana do Livramento. Tem a parte de genética que tá sendo perdida, porque tem muitas cabanhas fortes, que a gente tem em Santana do Livramento, que estão desistindo da produção... o tosqueador também está perdendo, porque o rebanho tá diminuindo... mas muita gente se foca só no cordeiro porque, "bah, a gente perdeu mil cordeiros lá em casa!"... mas com esses mil cordeiros, também perdeu o caminhoneiro, que começa a ter prejuízo, o da esquila também teve prejuízo... porque antigamente tu contratava cinco, mas agora tu contrata só dois para fazer a tosquia... e a parte genética, nem se fala... tem toda uma rede que envolve o produtor, a lã, o caminhoneiro, o próprio peão, que está dentro da propriedade... antigamente, tu chegava dentro de uma propriedade e tinha cinco, mas hoje tem um... às vezes tem só o produtor, nos finais de semana. Então, é importante que não se dimensione isso só pelo cordeiro, mas é toda uma cultura nossa... de um rebanho que ficou anos e anos cultivando uma genética. São coisas muito mais graves, e que o pessoal de gravata, em Brasília, muitas vezes não enxerga. (Transcrição, maio de 2015).

Para Bacchetta (2009), haveria razões suficientes para se acreditar em uma conexão entre expansão do javali e expansão dos monocultivos florestais. De acordo com suas observações no norte do Uruguai, "todos os vizinhos dos plantios coincidem em afirmar que esse animal se multiplicou e ampliou seus deslocamentos favorecidos por estas condições" (Bacchetta, 2009, p. 57). Isso porque, "tradicionalmente, o javali se abrigava na mata ciliar dos rios e arroios. Hoje, os plantios lhe dão proteção porque não há vigilância para evitar isso" (Bacchetta, 2009, p. 57).

Como registramos anteriormente, outro organismo exótico frequentemente evocado em conjunto com o javali é a gramínea sul-africana Eragrostis plana Nees, conhecida no Rio Grande do Sul como capim-annoni. Esse nome 
advém do pecuarista e agricultor Ernesto José Annoni, cuja empresa auxiliara na dispersão da planta nos estados do sul do Brasil, durante os anos 1970. $\mathrm{O}$ entusiasmo de Annoni com a erva provinha de certas expectativas quanto à sua maior eficiência na conversão de biomassa, o que auxiliaria a superar a histórica baixa produtividade da pecuária extensiva a campo nativo. Assim como em muitos outros casos de introdução de gramíneas ao redor do mundo (Simberloff, 2013), o experimento acabou não cumprindo suas expectativas, e o capim-annoni tornou-se um tormento para pecuaristas e ambientalistas.

Alguns estudos estimam que a gramínea invasora cobre uma área de mais de um milhão de hectares somente no Rio Grande do Sul, sem contar os dois outros estados meridionais do país (Borges de Medeiros; Saibro; Focht, 2009). Em Livramento e região, não é incomum que se compare a "guerra" contra o javali à "guerra" contra o capim-annoni, como se ambos formassem uma dupla ameaça animal-vegetal. Tal como declarou o presidente do Clube de Tiro local durante a audiência pública supramencionada:

Se a gente pudesse exterminar o anonni, a gente terminava. Por quê? Porque é exótico. É invasor e é exótico. Ao meu ponto de vista, se a gente puder exterminar o javali por ser invasor e exótico, a gente também devia. O Clube de Tiro está aqui para proporcionar [uma solução] pessoas que estão sofrendo com isso, com o javali. (Transcrição, maio de 2014).

No entanto, ao contrário do tom de indignação que permeia as reações dos pecuaristas à ação dos suínos ferais, suas menções ao eucalipto e ao capim-annoni se revestem no mais das vezes de um tom um tanto mais resignado, próximo ao que alguns psicanalistas e filósofos ambientais contemporâneos têm chamado de "solastalgia" (Albrecht, 2005), isto é, o sentimento melancólico de impotência, individual ou social, acarretado por mudanças socioambientais de difícil identificação ou para além do controle dos sujeitos afetados. De acordo com Dominique Lestel (2011, p. 42, grifo do autor), essa diferença de percepção entre a ameaça vegetal e animal se origina da própria relação que estabelecemos com a temporalidade de cada ser, pois

[...] uma verdadeira interatividade vem com um homem que pode coordenar suas ações, através de encadeamentos complexos e significantes, com as do animal, pelo viés do amansamento, da domesticação, da caça, do ritual de combate etc. Esse não é o caso do vegetal. [...] A temporalidade das ações vegetais, cuja 
existência não se coloca em dúvida, é por demais lenta para representar qualquer significado para o homem. Concorde-se ou não, a mobilidade interativa com o homem é um atributo maior de inteligência. Sob essa ótica é interessante notar que a ameaça vegetal, por exemplo, é sempre percebida em termos de "massa" ou de "coletivo" e vivenciada sob o modo da "propagação", como uma epidemia, mais do que sob o da "estratégia", como pelo animal.

Ganha relevância, nesse sentido, o fato de o comportamento do javali ser comparado, no mais das vezes, ao do abigeatário ou ladrão de gado, personagem frequente no folclore e nos registros policiais da zona fronteiriça. Eis o que nos ponderou um pecuarista, certa feita, sobre os "métodos de trabalho" comuns entre o abigeatário e o javali:

Só pra tu ter uma ideia, eu tô em zona de abigeato, de roubo de gado. E os ladrões de gado, assim como os javalis, usam o mesmo expediente: eles procuram não se exibir pra nós, né? Eles trabalham no horário em que tu tá mais recolhido, de noite ou no clarear do dia. Se bem que o ladrão de gado é racional, e o bicho é irracional: ele erra o cálculo dele - se é que ele faz o cálculo -, e aí a gente vê eles. Mas normalmente a gente não vê o javali, só sente o efeito. (Transcrição, junho de 2014).

Formulando de outra maneira, poderíamos dizer que, na percepção dos criadores, ambas as personagens compartilham um mesmo ethos furtivo, uma maneira de habitar a paisagem da Campanha simétrica e inversa àquela das lidas lícitas. Em contraste com as EEIs vegetais que grassam sobre o Pampa sob a forma de uma "ameaça silenciosa" que inviabiliza lenta e anonimamente a reprodução da pecuária a campo nativo, a animalidade do javali, isto é, sua capacidade de estabelecer "encadeamentos complexos e significantes" (Lestel, 2011, p. 42) com o humano em um regime temporal de mesma escala, faz com que seja percebido como sujeito dotado de intencionalidade, ao qual se pode atribuir uma responsabilidade direta.

Como no caso do abigeatário, seu horário de "trabalho" é à noite, momento em que os criadores e seus peões estão mais recolhidos. Da mesma forma, os dois agentes deixam marcas similares de sua passagem pela propriedade, como cercas danificadas, rastros e pegadas. Identificado como agente intencional pelos pecuaristas e portador de uma índole "bandida", o javali se torna antagonista de um conflito pensado não apenas em termos econômicos 
e ecológicos, mas também morais e atinentes aos códigos de honra que permeiam a vida e as relações de trabalho e propriedade na Campanha.

Nos episódios de furto de ovelhas e reses, é frequente que se deixem apenas as cabeças dos animais a campo, como desafio e afronta ao proprietário. Analogamente, o javali deixa as carcaças semidevoradas dos cordeiros e novilhos que consome como lembrança de sua presença feral. Marlene Spaniol (2015), ademais, registra que o abigeato é a ocorrência policial mais frequente nos municípios da fronteira brasileiro-uruguaia, respondendo a $60,16 \%$ dos crimes registrados entre 2012 e 2013 em Livramento (444 ocorrências) e 67,4\% em Quaraí (122 ocorrências). Já José Luiz Bica de Mélo (2004, p. 141) afirma que, por trás do que chama de "usos políticos do abigeato" na fronteira brasileiro-uruguaia, existiriam "interesses de diversos setores: dos consumidores, dos comerciantes de carne clandestina e também dos próprios proprietários dos animais".

Nesse contexto, destaca-se a tradicional desconfiança dos órgãos de vigilância sanitária quanto à mobilidade dos rebanhos para além dos limites das propriedades em que estão registrados. Em verdade, esse é um tópico bastante sensível na relação entre inspetores veterinários, já que sempre há o risco de uma alegação de abigeato ocultar o extravio intencional de animais para outra propriedade ou mesmo para o outro lado da fronteira, sem que isso seja notificado. Ao longo do chamado corredor internacional, extenso caminho de terra que corre junto à divisa entre os dois países, é comum que se abaixe a cerca com o intuito de que o gado atravesse a linha por conta própria.

$\mathrm{Na}$ paisagem pastoril da Campanha, vigora certo continuum entre as habilidades requeridas pelas lidas campeiras "lícitas" e suas contrapartidas "ilícitas", como o furto direto de reses a campo ou seu extravio indireto para o outro lado da fronteira. Em um contexto de múltiplas tensões envolvendo proprietários e trabalhadores rurais, isso faz com que os próprios peões de estância sejam encarados, muitas vezes, como ladrões de gado em potencial. Quanto a esse ponto, é relevante registrar que um manual da Brigada Militar publicado em 2002 sobre "como evitar o abigeato", assim recomendava:

Confira seus rebanhos periodicamente, em especial o de ovinos, no mínimo de 15 em 15 dias, para apurar se está sofrendo a ação de abigeatários;

Exija, quando for empregar alguém, referências, por escrito, do emprego anterior; informações da Brigada Militar e, se possível, folha corrida de antecedentes junto à Polícia Civil; 
Cuidado quando despedir um empregado e o mesmo responder com frases irônicas do tipo: - Pense bem no que o senhor vai fazer...; - O senhor não deveria me despedir...; - Isso não vai ficar assim...; Nestes casos, avise a Brigada Militar, dando o nome do elemento, endereço e se possível, o motivo da dispensa. (Brigada Militar, 2002 apud Bica de Mélo, 2004, p. 142-143).

Em suma, tudo leva a crer que a analogia entre o javali e o ladrão de gado se nutre da percepção de que ambos compartilham uma etologia da ilicitude que equaliza o furto à predação, num sentido ecológico das práticas, e a feralização à traição, num sentido moral que, por sua vez, aproxima o caso do javali ao dos cães pastores que se asselvajam e passam a atacar os rebanhos que outrora protegiam. Também neste caso, os animais são tratados como "bandidos", sendo o sacrifício dos mesmos um expediente punitivo bastante recorrente.

Em sua etnografia sobre a relação entre lobos e pastores no Quirguistão, Nicolas Lescureux (2006, p. 470, tradução nossa) aponta que, "para os olhos dos criadores [...], certos comportamentos lupinos seriam diretamente relacionados a práticas humanas". A longa coabitação entre uns e outros teria levado a uma percepção do lobo não como objeto ou simples elemento do mundo natural, mas como "um vizinho, um competidor, e até mesmo como um predador antropófago; em suma, um alter ego" (Lescureux, 2006, p. 472, tradução nossa).

Em um sentido histórico, confrontos agonísticos entre humanos e animais conformam a paisagem da Campanha da mesma maneira que as introduções biológicas tratadas no item anterior. Sua constituição como fronteira pastoril remete a um passado no qual o gado era mais caçado (preado) do que criado, e mesmo após a consolidação da propriedade sobre a terra e os animais, modos de apreensão positiva dos rebanhos continuaram persistindo, como a doma, a marcação e o rodeio.

Já sua constituição como fronteira política forjou-se através do constante enfrentamento entre luso-brasileiros e castelhanos pela "posse de terra e gados" (Freitas 1980, p. 24). Nesse confronto, o abigeato e o extravio de reses era um dos dispositivos bélicos mais frequentes, como bem relata Saint-Hillaire (2002, p. 112) em várias passagens de sua Viagem ao Rio Grande do Sul:

Os portugueses, após a guerra, tomaram dos espanhóis um número considerável de animais; são acusados por estes de terem iniciado estes roubos, antes mesmo de começadas as hostilidades. Por seu turno, os portugueses acusam os 
espanhóis de terem sido os primeiros a dar exemplo desses furtos [...]. Segundo o caráter bem conhecido dos gaúchos, é lícito crer que, logo proclamada a independência, aproveitaram eles os primeiros momentos de desordem a fim de pilhar o gado nas estâncias dos portugueses e que estes, por sua vez, também o roubavam das estâncias espanholas.

Assim, na história técnica e social do Pampa, as taskscapes - ou "paisagens técnicas" (Ingold, 2000) - pastoril e política se confundem de tal modo que é difícil dissociá-las, quanto mais estabelecer os limites precisos entre as operações de guerra, preia e furto. Nesse sentido, Barrán (2012) aponta em sua Historia de la sensibilidad en el Uruguay que os mesmos meios empregados pela pecuária tradicional da Campanha - a faca, o laço, a boleadeira, a garrocha, etc. - também serviram, classicamente, para fazer a guerra. E a guerra, como vimos, sempre teve nessa região um componente de roubo, de extravio, de pilhagem. Destarte, não é por pura coincidência que as reações sociais ao javali na Campanha gaúcha se desdobrem em um idioma da beligerância, um idioma da guerra.

Como prega um texto de apresentação da Associação Gaúcha de Controle do Javali Asselvajado (Agaja), o javali seria "o único entre os predadores nocivos e exóticos a compensar parcialmente suas perdas na agricultura e criação com o consumo de sua saborosa carne, quando este lhes retorna o que surrupiou". A uma forma de aquisição violenta, opõe-se outra forma de aquisição violenta. Por meio da caça, homem e javali se quitam. Como espólio, ademais, pode-se consumir a sua carne, com todas as reverberações simbólicas de uma incorporação da sua potência ameaçadora, no sentido proposto por Carlos Fausto (2001) e outros etnólogos amazonistas.

\section{Considerações finais}

Ao longo deste artigo, procuramos situar o problema dos javalis no Pampa brasileiro-uruguaio em um conjunto de coordenadas mais amplas, que vão além da sua definição como EEI e único grande vertebrado cuja caça é permitida no Brasil. Pelo conjunto de configurações socioambientais aqui elencadas, tendemos a concordar com Lidström et al. (2015) quando estes argumentam que narrativas sobre invasões biológicas necessitam ser desdobradas para além da agência dos organismos invasores em si, mas também 
devem levar em conta sua articulação com processos de maior complexidade e mais longa duração.

No caso do javali na fronteira sul, a metáfora da predação com o abigeato mostrou-se metonímica de tensões sociais que ultrapassam a agência individual do Sus scrofa em si, espelhando e dramatizando questões que se efetivam num plano propriamente social e político das relações humanas delimitado pela questão da propriedade. Já as analogias com o capim-annoni e os monocultivos florestais se articulam em uma fenomenologia apocalíptica (Dalla Bernardina, 2009) da pecuária sulina como forma de vida declinante, na esteira do avanço de outros cultivos sobre suas terras tradicionais e de sua condição cada vez mais marginal no sistema agropecuário gaúcho e nacional.

\section{Referências}

ALBRECHT, G. Solastalgia, a new concept in human health and identity. Philosophy Activism Nature, Melbourne, n. 3, p. 41-44, 2005.

ÁLVAREZ, M. F. T. Tornar-se nativo / a resistência do liso. In: STEIL, C. A.; CARVALHO, I. C. M. (Org.). Cultura, percepção e ambiente: diálogos com Tim Ingold. São Paulo: Terceiro Nome, 2012. p. 153-173.

BACCHETTA, V. L. A fraude da celulose. Porto Alegre: Dacasa, 2009.

BARETTA, S. R. D.; MARKOFF, J. Civilization and barbarism: cattle frontiers in Latin America. Comparative Studies in Society and History, Cambridge, v. 20, n. 4 , p. 587-620, 1978.

BARRÁN, J. P. Historia de la sensibilidad en el Uruguay. Montevideo: Banda Oriental, 2012.

BARRIOS-GARCÍA, M. N.; BALLARI, S. A. Impact of wild boar (Sus scrofa) in its introduced and native range: a review. Biological Invasions, Dordrecht, v. 14, n. 11, p. 2283-2300, 2012.

BEVILAQUA, C. Espécies invasoras e fronteiras nacionais: uma reflexão sobre os limites do Estado. Revista Anthropológicas, Recife, v. 24, n. 1, p. 104-123, 2013. 
BICA DE MÉLO, J. L. O velho e o novo da violência rural na fronteira BrasilUruguay. Sociedade e Estado, Brasília, v. 19, n. 1, p. 121-150, 2004.

BORGES DE MEDEIROS, R.; SAIBRO, J. C. de; FOCHT, T. Invasão de capim-annoni (Eragrostis plana Nees) no bioma Pampa do Rio Grande do Sul. In: PATTA PILAR, V. de et al. (Ed.). Campos sulinos: conservação e uso sustentável da biodiversidade. Brasília: Ministério do Meio Ambiente, 2009. p. 317-330.

BRASIL. A Convenção sobre Diversidade Biológica - CDB. Brasília: Ministério do Meio Ambiente, 2000.

COLAUTTI, R.; Mc ISAAC, H. A neutral terminology to define invasive species. Diversity and Distributions, Hoboken, v. 10, n. 2, p. 135-141, 2004.

COMTE-SPONVILlE, A. Dicionário filosófico. São Paulo: Martins Fontes, 2003.

CROSBY, A. Imperialismo ecológico: a expansão biológica da Europa 9001900. São Paulo: Companhia das Letras, 2011.

DALLA BERNARDINA, S. Le gibier du apocalypse: chasse et théorie du complot. Ethnologie française, Paris, v. 39, n. 1, p. 79-88, 2009.

DAVIS, M. Don't judge species on their origins. Nature, London, v. 474, p. 153-154, 2011.

DEBERT, A. J.; SCHERER, S. B. O javali asselvajado: ocorrência e manejo da espécie no Brasil. Natureza e Conservação, Curitiba, v. 5, n. 2, p. 31-44, 2007.

FARINATTI, L. A. E. Confins meridionais: famílias de elite e sociedade agrária na fronteira sul do Brasil (1825-1865). 2007. Tese (Doutorado em História)-Instituto de Filosofia e Ciências Sociais, Universidade Federal do Rio de Janeiro, Rio de Janeiro, 2007.

FAUSTO, C. Inimigos fiéis: história, guerra e xamanismo na Amazônia. São Paulo: Edusp, 2001. 
FREITAS, D. O mito da "produção sem trabalho". In: FREITAS, D.; DACANAL, J. H.; GONZAGA, S. (Org.). RS: cultura e ideologia. Porto Alegre: Mercado Aberto, 1980. p. 7-24.

GONZAGA, S. As mentiras sobre o gaúcho: primeiras contribuições da literatura. In: FREITAS, D.; DACANAL, J. H.; GONZAGA, S. (Org.). RS: cultura e ideologia. Porto Alegre: Mercado Aberto, 1980. p. 113-131.

INGOLD, T. Hunters, pastoralists and ranchers: reindeer economies and their transformations. Cambridge: Cambridge University Press, 1980.

INGOLD, T. The perception of the environment: essays on livelihood, dwelling and skill. London: Routledge, 2000.

LARSON, B. M. H. The war of the roses: demilitarizing invasion biology. Frontiers in Ecology and the Environment, Washington, v. 3, n. 9, p. 495-500, 2005.

LESCUREUX, N. Towards the necessity of a new interactive approach integrating ethnology, ecology and ethology in the study of the relationship between Kyrgyz stockbreeders and wolves. Social Science Information, London, v. 45, n. 3, p. 463-478, 2006.

LESTEL, D. A animalidade do humano e as "comunidades híbridas". In: MACIEL, M. E. (Org.). Pensar/escrever o animal: ensaios de zoopoética e zoopolítica. Florianópolis: Editora da UFSC, 2011. p. 23-54.

LÉVI-STRAUSS, C. O pensamento selvagem. Campinas: Papirus, 1989.

LIDSTRÖM, S. et al. Invasive narratives and the inverse of slow violence: alien species in science and society. Environmental Humanities, Durham, v. 7, n. 1, p. 1-40, 2015.

LOMBARDI, R. et al. El jabalí en el Uruguay. Montevideo: Centro Interdisciplinario para el Desarrollo, 2007.

LOWE, S. et al. 100 of the world's worst invasive alien species: a selection from the Global Invasive Species Database. Auckland: ISSG, 2004. 
OLIVEIRA, A. E. S.; MACHADO, C. J. S. Quem é quem diante da presença de espécies exóticas no Brasil? Uma leitura do arcabouço institucional-legal voltada para a formulação de uma Política Pública Nacional. Ambiente \& Sociedade, São Paulo, v. 12, n. 2, p. 373-387, 2009.

OLIVEIRA, A. E. S.; PEREIRA, D. G. Erradicação de espécies exóticas invasoras: múltiplas visões da realidade brasileira. Desenvolvimento e Meio Ambiente, n. 21, p. 173-181, 2010.

OLIVEIRA VIANA, F. J. Populações meridionais do Brasil. Brasília: Senado Federal, 2005. (Edições do Senado Federal, v. 27).

PEARCE, F. The new wild: why invasive species will be nature's salvation. London: Icon Books, 2015.

PESAVENTO, S. J. História do Rio Grande do Sul. Porto Alegre: Mercado Aberto, 1994.

SAGOFF, M. Who is the invader? Alien species, property rights and the Police power. In: ROTHERHAM, I. D; LAMBERT, R. A. (Ed.). Invasive and introduced plants and animals: human perceptions, attitudes and approaches to management. London: Earthscan, 2011. p. 79-108.

SAINT-HILlAIRE, A. Viagem ao Rio Grande do Sul. Brasília: Senado Federal, 2002.

SARMIENTO, D. F. Facundo. Buenos Aires: Editorial Losada, 2004.

SIMBERLOFF, D. The rise of modern invasion biology and American attitudes towards introduced species. In: ROTHERHAM, I. D; LAMBERT, R. A. (Ed.). Invasive and introduced plants and animals: human perceptions, attitudes and approaches to management. London: Earthscan, 2011. p. 121-135.

SIMBERLOFF, D. Invasive species: what everyone needs to know. Oxford: Oxford University Press, 2013.

SKEWES, O.; JAKSIC, F. M. History of the introduction and present distribution of the European Wild Boar (Sus scrofa) in Chile. Mastozoología Neotropical, v. 22, n. 1, p. 113-124, 2015. 
SPANIOL, M. (Re)estruturação das ações de segurança pública, prevenção, repressão e controle, através da Enafron, ante as principais incidências criminais na fronteira Brasil-Uruguai. In: MALMANN, M. I.; MARQUES, T. C. S. (Org.). Fronteiras e relações: Brasil-Uruguai. Porto Alegre: Edipucrs, 2015. p. 183-198.

SUBRAMANIAM, B. The aliens have landed! Reflections on the rhetoric of biological invasions. Meridians: feminism, race, transnationalism, Bloomington, v. 2, n. 1, p. 26-40, 2001.

THOMPSON, C. When elephants stand for competing philosophies of nature. In: LAW, J.; MOL, A. (Ed.). Complexities: social studies of knowledge practices. Durham: Duke University Press, 2002. p. 167-190.

TSING, A. L. Empowering nature, or: some gleenings in bee-culture. In: YANAGISAKO, S.; DELANEY. C. (Ed.). Naturalizing power: essays in feminist cultural analysis. New York: Routledge, 1995. p. 113-143.

VIVEIROS DE CASTRO, E. Metafísicas canibais: elementos para uma antropologia pós-estrutural. São Paulo: Cosac Naify: n-1 edições, 2015.

WOODS, M.; MORIARTY, P. V. Strangers in the land: the problem of exotic species. Environmental Values, Cambridge, v. 10, n. 2, p. 163-191, 2001. 